\title{
Clinical experience of lymphangioleiomyomatosis in the UK
}

\author{
S R Johnson, A E Tattersfield
}

\begin{abstract}
Background-Lymphangioleiomyomatosis is a rare lung disease that affects only women. No controlled trials of management have been performed and, until such data are available, management must be based on clinical experience. This study provides data on the natural history of lymphangioleiomyomatosis in the UK and compares this with experience from other centres.

Methods-We tried to identify all cases of lymphangioleiomyomatosis in the UK over a five year period by contacting all chest physicians. Cases were confirmed by lung biopsy or history and high resolution computed tomographic (CT) scanning. Details of disease and management were obtained from hospital notes.
\end{abstract}

Results-The 50 patients who fitted the diagnostic criteria for lymphangioleiomyomatosis had a median age at onset of 35 years (range 22-50). Five presented when postmenopausal (four taking hormone replacement therapy). Pneumothorax and dyspnoea were the most common presenting features. Extrapulmonary presentations included renal angiomyolipomas (3) and lymphangiomyomas (2). Only half the patients were assessed for renal angiomyolipoma and six were identified. Thirty patients had had one or more pneumothoraces, of which two thirds recurred if treated conservatively. Chylous effusions occurred in 11 patients, five requiring surgery. Pregnancy was uncommon once the diagnosis was made $(n=7)$, but was associated with an increase in complications. Half the patients were taking a $\beta$ agonist and many showed a bronchodilator response in the laboratory. Thirty six patients had received hormone treatment.

Conclusions-Our UK five year period prevalence was one per 1.1 million population. Since prophylactic interventions are sometimes indicated for renal angiomyolipoma, these data suggest that screening for angiomyolipoma, ideally by CT scanning, may be underused. Patients need to be aware of the increase in complications associated with pregnancy. Recurrence rate of pneumothorax was high in those not treated surgically. Hormone treatment was used variably and controlled trials are needed to determine their role and the optimum duration and dose.

(Thorax 2000;55:1052-1057)
Keywords: lymphangioleiomyomatosis; angiomyolipoma; pneumothorax; chylous effusion; management

Lymphangioleiomyomatosis (LAM) is a rare disease of unknown aetiology that is only seen in women. The disease causes dyspnoea, pneumothorax, chylous pleural effusions, haemoptysis, and eventually respiratory failure. ${ }^{1-3}$ Extrapulmonary manifestations include abdominal and pelvic masses occurring along the axial lymphatics (now termed lymphangiomyomas), chylous ascites, and renal angiomyolipomas. ${ }^{3-7}$ The pulmonary manifestations and renal angiomyolipomas seen in LAM are also seen in some patients with tuberous sclerosis complex (TSC). ${ }^{8}$ Hormonal factors are thought to play a role as the disease only affects women who are generally premenopausal, may be exacerbated by exogenous oestrogens, ${ }^{10}$ and some LAM cells express oestrogen and progesterone receptors. ${ }^{11}$ Treatment consists of supportive management and may include hormonal therapy (either oestrogen depletion or exogenous progesterone). ${ }^{12} 13$

There are no controlled trials of treatment of LAM and few data to answer important questions concerning the best management of patients. Treatment therefore has to be based on experience. The purpose of this study is to report the experience of a national group of patients in the UK in the light of recent developments in our understanding of the disease and experience elsewhere with the aim of making some recommendations for patient management.

\section{Methods}

In $1994-5$ we tried to identify all patients with LAM in the UK who were alive or who had died within the previous five years, as described previously. ${ }^{13}$ We wrote to chest physicians on the British Thoracic Society (BTS) register asking for the names of patients with LAM who were alive or who had died within the last five years and then asked the physicians and patients for permission to study their hospital notes. Further cases were recruited by word of mouth from physicians, pathologists, and surgeons. The Nottingham City Hospital research ethics committee approved the study.

Details of the patient's illness were obtained by visiting the hospital and reviewing the hospital notes (40 cases); when this was not possible the hospital notes were sent to us for review (seven cases) or information was provided by the patient's physician (three cases). Data extracted from the patient's case notes included demographic details and information on presentation, date and mode of
26 July 2000

Accepted for publication

24 August 2000 
Table 1 Details of patients in whom onset of symptoms occurred when postmenopausal

\begin{tabular}{llll}
\hline $\begin{array}{l}\text { Age at first } \\
\text { symptom }\end{array}$ & Age at menopause & Menopause & $\begin{array}{l}\text { HRT duration at first } \\
\text { symptom (years) }\end{array}$ \\
\hline 45 & 45 & Natural & $<1$ \\
48 & 37 & Oophorectomy & 11 \\
42 & 40 & Natural & 2 \\
49 & 47 & Natural & 2 \\
50 & 45 & Natural & 0 \\
\hline
\end{tabular}

diagnosis, lung function, presence of angiomyolipoma, pneumothorax, pleural effusions, any other extrapulmonary manifestations, any treatment or surgical intervention, gynaecological history including pregnancy, other medical history, and details of screening for TSC. The diagnosis of LAM was accepted when confirmed by open lung biopsy specimens or when there was a classical computed tomographic (CT) scan of the thorax and compatible clinical history. Patients with a diagnosis of TSC were excluded from the study.

Disease duration was calculated as months since the first symptom that could be attributed to LAM. Follow up data on survival was obtained when necessary by contacting physicians and, when relevant, ascertaining the date and cause of death.

Presenting features are defined as the first symptom or event (such as pneumothorax) recorded in the hospital notes that was likely to be due to the disease; only one presenting feature was allowed per case. The incidence of complications was assessed as the total number of pneumothoraces, chylous effusions, and related thoracic surgical procedures per patient year. Treatment of pneumothoraces was categorised as non-surgical (observation, aspiration, intercostal drainage and/or pleurodesis via an intercostal drain) or surgical (any surgical procedure). The rate of recurrence in the ipsilateral hemithorax was determined for each pneumothorax.

Values for forced expiratory volume in one second $\left(\mathrm{FEV}_{1}\right)$, forced vital capacity (FVC), transfer factor for carbon monoxide (TLCO), and total lung capacity (TLC) at presentation are given as percentage predicted values. ${ }^{14}$ When lung function was reduced temporarily because of complications such as a pneumothorax or recent surgery, the presenting value was taken as the first measurement recorded once the pleural effusion had resolved, or six months following a thoracotomy and two months following a pneumothorax or longer if lung function continued to rise after these times.

The effect of pregnancy on the course of the disease was assessed by comparing the incidence of complications of LAM in patients during pregnancy with the incidence in all patients when not pregnant using Poisson regression (Egret Serc, Seattle, USA).

\section{Results}

Fifty seven patients who had been given a diagnosis of LAM were identified, although three had TSC with LAM and are not included. Of the remainder, 50 fitted our diagnostic criteria for LAM, giving a minimum five year period prevalence in the UK of one case per 1.1 million population (or one per 373000 women aged $16-65$ years).

The diagnosis of LAM was made in 41 cases from lung biopsy specimens and in nine by CT scanning and history as described. ${ }^{13}$ The lung biopsy specimens were taken during surgery for a pneumothorax or pleural effusion in 15 patients. The median time to diagnosis from the onset of symptoms was 4.3 years (ranging from a few days to 15 years).

Follow up data were available for 48 of the 50 patients. Seven had died at the time of writing, three from respiratory failure due to LAM, three following lung transplantation, and one from breast cancer. The median duration of disease since the onset of symptoms in survivors was 8.75 years (range $0.9-28$ ), and in those who had died it was also 8.75 years (range $4.2-10$ ).

\section{PRESENTATION}

The median age at the onset of symptoms of LAM was 35 years (range 22-50). Five patients developed their first symptom after the menopause, in four cases when taking oestrogen based hormone replacement therapy (table 1).

\section{Clinical features}

Data were available for 49 of the 50 patients. Pneumothorax and dyspnoea were the most common presenting features, occurring in 19 and 18 patients, respectively, followed by chylous effusion in three patients, cough in two, and chest pain in two. In five patients the initial presentation was caused by extrapulmonary LAM, two with a pelvic lymph node mass causing weight loss and three with pain and bleeding from a renal tumour. The renal manifestations (two angiomyolipomas, one sarcoma) preceded respiratory symptoms by $4-9$ years.

\section{Lung function}

At presentation most patients had airflow obstruction, relatively normal lung volumes, and a low TLCo. The median (range) values at presentation or as soon as available thereafter for $\mathrm{FEV}_{1}$, FVC (both $\left.\mathrm{n}=47\right)$, TLC ( $\mathrm{n}=30$ ), and TLCO $(n=35)$ were $65(22-120) \%, 82(27-$ $141) \%, 98(67-142) \%$ and $62(17-109) \%$ predicted, respectively. There was considerable variation in lung function between patients at presentation.

\section{Renal angiomyolipoma}

Of 48 patients on whom data were available, six were found to have a renal angiomyolipoma (five single, one multiple). Three patients had presented with bleeding (two had a nephrectomy and one a renal embolisation), one with a mass, and one with loin pain (both had a nephrectomy). An additional angiomyolipoma was identified following screening. Fifteen patients $(36 \%)$ had been screened for angiomyolipomas (10 with ultrasound, five with CT scanning). A further patient had a renal sarcoma. 


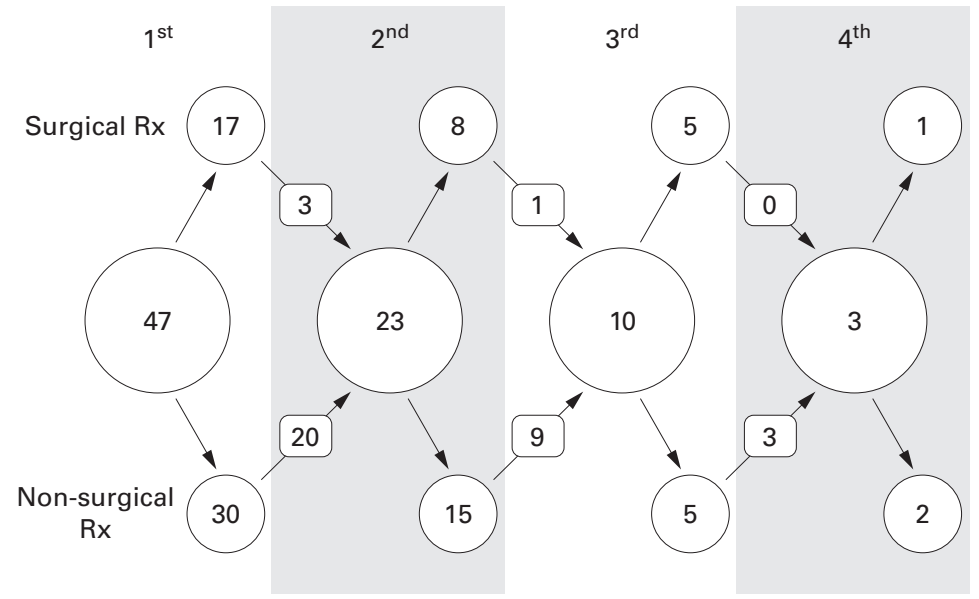

Figure 1 Management of pneumothorax: large circles show number of pneumothoraces for each recurrence in the ipsilateral hemithorax, upper small circles are those treated surgically, and the lower circles show those treated non-surgically. Numbered arrows denote the number of recurrences in each group. For example, 47 patients had a first pneumothorax, 30 were treated conservatively, and in 20 of these cases there was a further pneumothorax on the same side. Seventeen patients were treated surgically and three of these recurred.

Table 2 Details of pregnancies in patients with lymphangioleiomyomatosis (LAM)

\begin{tabular}{|c|c|c|c|c|}
\hline $\begin{array}{l}\text { Age when } \\
\text { pregnant }\end{array}$ & Parity* & $\begin{array}{l}\text { Complications during } \\
\text { pregnancy }\end{array}$ & $\begin{array}{l}\text { Interventions during } \\
\text { pregnancy }\end{array}$ & Delivery \\
\hline \multicolumn{5}{|c|}{ LAM presenting in pregnancy: } \\
\hline 27 & $1 / 1$ & $\begin{array}{l}\text { Bilateral } \\
\text { pneumothoraces }\end{array}$ & Surgical pleurectomy & $\begin{array}{l}\text { Caesarean section } \\
32 \text { weeks }\end{array}$ \\
\hline 32 & $1 / 1$ & Pneumothorax & Intercostal drain & $\begin{array}{l}\text { Caesarean section } \\
38 \text { weeks }\end{array}$ \\
\hline 28 & $2 / 2$ & $\begin{array}{l}\text { Bilateral chylous } \\
\text { effusions }\end{array}$ & Intercostal drain & Not specified \\
\hline 30 & $1 / 1$ & Chylous effusion & $\begin{array}{l}\text { Thoracotomy, } \\
\text { thoracic duct } \\
\text { ligation, OLB, } \\
\text { pleurectomy }\end{array}$ & Uncomplicated \\
\hline \multicolumn{5}{|c|}{ Pregnancies after LAM diagnosed ${ }^{\star \star}$ : } \\
\hline 32 & $1 / 1$ & Pneumothorax & $\begin{array}{l}\text { Thoracotomy, OLB } \\
\text { and pleurectomy }\end{array}$ & $\begin{array}{l}\text { Caesarean section } \\
38 \text { weeks }\end{array}$ \\
\hline 36 & $2 / 4$ & None & $\begin{array}{l}\text { Termination at } 12 \\
\text { weeks }\end{array}$ & \\
\hline 29 & $1 / 1$ & None & None & $\begin{array}{l}\text { Caesarean section } \\
38 \text { weeks }\end{array}$ \\
\hline
\end{tabular}

OLB $=$ open lung biopsy.

$\star$ Successful pregnancies/all pregnancies.

${ }^{\star \star}$ LAM diagnosed at 108,44 , and 39 months before pregnancy, respectively.

Lymphangiomyomas and cutaneous swellings

Five patients had abnormal cystic or solid masses (lymphangiomyomas), three in the abdomen and two in the pelvis. Three were found at presentation and two when investigating the cause of chylous effusions. Five patients had cutaneous swellings, two in the abdominal wall and one in the buttock, upper thigh and neck. Four occurred intermittently and all were thought to represent localised oedema. Four of the five patients had a chylous effusion, ascites, or both, and two had lymphangiomyomas.

SCREENING FOR TUBEROUS SCLEROSIS

Three patients had TSC and LAM and are not included in the series. Two had obvious TSC with classical cutaneous and neurological features whereas the diagnosis in the third patient was only made when she had a pneumothorax and other features of TSC were recognised. Only one patient with isolated LAM had had full screening for TSC (dermatological examination with Woods light, cranial CT scan, cardiac and renal ultrasound) and one had had limited screening (dermatological examination and genetic analysis).
INCIDENCE AND MANAGEMENT OF COMPLICATIONS

Data from the time of presentation were available from 48 patients giving a time span of 412 patient years. The incidence of complications and interventions described below cover the total period including pregnancy.

\section{Pneumothorax}

There were 83 pneumothoraces in 30 patients with 23 patients having more than one pneumothorax and four having simultaneous bilateral pneumothoraces. Four pneumothoraces required no intervention and three responded to simple aspiration. Of the other 76 episodes, 45 resolved with intercostal drainage but 31 required surgical procedures (pleural abrasion (2), pleurodesis (11), pleurectomy (16), thorascopic pleurodesis and long term chest drainage (1), and bullectomy plus pleurodesis (1)). Overall, approximately half of the pneumothoraces recurred, recurrence rates being much higher in those treated conservatively (fig 1).

\section{Chylous effusions}

Eleven patients had chylous pleural effusions. Two small effusions received no intervention while the remainder were treated initially by aspiration or intercostal drainage. Seven patients needed further procedures-namely, pleurodesis via an intercostal drain (2), pleurectomy (2), pleurodesis, pleurectomy and thoracic duct ligation (2), and bilateral thorascopic drainage and pleurodesis (1). Two patients had a medium chain triglyceride diet and two had progesterone treatment as an adjunct to other treatments, although it is difficult to determine whether these interventions were of benefit.

\section{EFFECT OF PREGNANCY}

Of the 50 patients, 28 had been pregnant and 27 had had children. All but seven patients had had all their children before the onset of symptoms. The seven patients developed their first symptom of LAM when pregnant or postpartum $(n=4)$ or became pregnant after LAM had been diagnosed $(n=3)$. Of the seven patients, one pregnancy was uncomplicated and one was terminated. The other five patients had complications during pregnancy with two developing a chylous pleural effusion and three having one or more pneumothoraces (table 2). Three patients required lung surgery during the pregnancy. The overall incidence of complications was 11 times higher during pregnancy than at other times $(95 \%$ confidence interval (CI) 5.3 to 25.0), $\mathrm{p}<0.001$ (table 3). There were insufficient lung function data to compare changes in lung function before and after pregnancy.

\section{TREATMENT}

$\beta$ agonists

Thirty six patients had airflow obstruction and 24 of these were taking a $\beta$ agonist. The response to salbutamol or terbutaline administered by metered dose inhaler or nebuliser according to local hospital procedures was 
Table 3 Complications during and outside pregnancy in patients with LAM (mean number of events per year of disease)

\begin{tabular}{lll}
\hline & Pregnant & Non-pregnant \\
\hline Patients & 7 & 47 \\
Patient years & 4.5 & 407 \\
Pneumothorax & 1.55 & 0.17 \\
Chylous effusion & 0.44 & 0.03 \\
Surgery & 0.66 & 0.06 \\
\hline
\end{tabular}

available for 22 patients and showed a median increase in $\mathrm{FEV}_{1}$ of $165 \mathrm{ml}$ (range $0-470 \mathrm{ml}$; $\mathrm{p}<0.00001)$. Eight patients showed an increase in $\mathrm{FEV}_{1}$ of $>15 \%$ from baseline.

\section{Hormonal manipulation}

The use of hormone therapy varied, with 13 patients having had no hormone treatment. Thirteen patients had received intramuscular medroxyprogesterone (most commonly $400 \mathrm{mg} / \mathrm{month}$, range 75-800) and nine had received oral progesterone (range $10-600 \mathrm{mg} /$ day). Four had been treated with tamoxifen and five with buserelin, either alone (1), with tamoxifen (2), or with progesterone and tamoxifen (2). Five patients had undergone an oophorectomy but this was performed for LAM in only one patient. Treatment was initiated at the time of diagnosis in 14 patients.

\section{Lung transplantation}

Five patients had undergone six lung transplantation procedures, either a single lung transplant (3), double lung transplant (2), or heart-lung transplant (1). Two patients had died from complications in the first week after the transplant operation and one from a lymphoma eight years after transplantation.

\section{Discussion}

INCIDENCE, CLINICAL FEATURES AND SURVIVAL We describe the clinical features and management of 50 women in the UK with LAM. The five year period prevalence is a minimum estimate since some patients may not have been identified. The figure is, however, very similar to those obtained from France where 75 patients have been identified from a population of 58 million $^{15}$ and the USA where 250 patients have been identified in a population of 263 million (data from the LAM Foundation, Cincinnati, Ohio). Although the disease appears to occur worldwide ${ }^{2}$ the prevalence has not been estimated in other countries.

The patients in our study were typical of patients in other series with respect to their symptoms, lung function, and disease duration. ${ }^{12716}$ There are no good data on life expectancy in patients with LAM as most attempts to estimate this have been biased toward survivors. In our study we tried to identify all patients within a defined period but, as most patients were still alive at the time of writing, we cannot yet assess survival. The median duration of disease among survivors is similar to that reported by Taylor and colleagues. ${ }^{1}$ There were long term survivors among our patients with five still alive more than 20 years after the onset of symptoms.
PNEUMOTHORAX AND PLEURAL EFFUSION Pneumothorax was common and frequently required surgical intervention. The high recurrence rate with conservative treatment suggests that surgery for pneumothorax should be considered earlier in LAM than in other diseases. Surgery was also an effective treatment for chylous pleural effusions although some responded to conservative treatment. Progesterone $^{1}$ and a medium chain triglyceride diet $^{17}$ have been advocated as specific treatment for chylous collections although evidence of benefit is limited to case reports. Their effects on the small number of patients in this study could not be assessed since the patients also underwent other procedures such as intercostal drainage and surgery.

\section{DIAGNOSIS AND MANAGEMENT OF}

EXTRAPULMONARY DISEASE

The incidence of angiomyolipomas and lymphangiomyomas was lower in our study than in other published series in which patients were screened by CT scanning. Among the 66 patients, renal angiomyolipomas (single or occasionally multiple) were identified in half the patients. ${ }^{5-7}$ One study screened for lymphangiomyomas and found retroperitoneal adenopathy in $75 \%$ and pelvic adenopathy in $10 \%$ of patients. ${ }^{7}$ Lymphangiomyomas are frequently asymptomatic but may be associated with ascites ${ }^{7}$ or localised cutaneous oedema, as in our study. Detecting lymphangiomyomas as soft tissue masses of fat density on CT scanning can strengthen the diagnosis of LAM when a tissue biopsy has not been performed. A diagnosis of angiomyolipoma is generally possible from the CT scan alone ${ }^{18}$ and early detection may avoid complications and enable renal tissue to be preserved. ${ }^{19}{ }^{20}$ Small tumours usually require observation with serial ultrasound scanning, but larger tumours may need treatment by planned intervention, including embolisation and nephron sparing surgery. The patients with symptomatic angiomyolipomas in our study tended to present with renal symptoms before the respiratory manifestations of the disease. Their low detection rate from screening in our study may reflect the small sample size and we suggest that patients suspected of having LAM should have an abdominal CT scan to detect renal angiomyolipomas and lymphangiomyomas.

SCREENING FOR TSC

Pulmonary LAM can occur as part of TSC and classical features such as epilepsy and mental retardation may not be present. ${ }^{521}$ TSC is an autosomal dominant condition with a high level of penetrance so making the diagnosis has important implications for the patient and the family. No women with apparently isolated LAM are known to have had a child with TSC, so the chances of a patient who presents with LAM having undiagnosed TSC or a germ line mutation in one of the two TSC genes is very small. Only two patients in our study had been screened for TSC and screening all patients would have a low pick up rate and may cause anxiety. We suggest that all 
patients undergo a careful family history and clinical examination for evidence of TSC and are only referred to a clinical geneticist if TSC is suspected.

PREGNANCY

Women with LAM are generally of childbearing age and issues relating to pregnancy may need to be discussed. Case reports have suggested that pregnancy can exacerbate the disease $^{22-24}$ and there is some evidence that women with LAM are less likely to become pregnant. ${ }^{25}$ In our study the incidence of complications was increased during pregnancy, although the numbers were small and other women may have had an uneventful pregnancy at a time when LAM was present but undiagnosed. Our findings are, however, compatible with previous observations that pregnancy is associated with an increased incidence of complications and patients should be aware of this before conception.

\section{$\beta$-AGONIST TREATMENT}

A high proportion of our patients were taking a $\beta$ agonist and the variable response to $\beta$ agonists in the laboratory may be an underestimate since reversibility testing was not performed according to a standard protocol and usually on one occasion only. Reversible airflow obstruction has been seen in up to $30 \%$ of patients in other studies. ${ }^{726} \mathrm{~A}$ trial of $\beta$ agonists may be warranted in patients with airflow obstruction, although the effects of regular use are unknown.

\section{HORMONE THERAPY}

The large differences in the use of hormone treatment probably reflect the fact that none is of proven efficacy. Although the evidence of benefit is probably best for progesterone, its effect may be short lived. ${ }^{13}$ There is little evidence on which to base dose recommendations although an intramuscular dose of $400 \mathrm{mg}$ per month or $10-20 \mathrm{mg} /$ day orally are often used. ${ }^{12}{ }^{13}$ Other treatments should probably be reserved for patients showing little clinical response to progesterone. ${ }^{27}$

\section{CONCLUSIONS}

This study shows considerable variation in the manifestations, natural history, and management of LAM in the UK, as in other countries. Certain clinical points emerge from this study which may help with management decisions. Screening for angiomyolipoma appears to be of value since it may enable renal tissue to be conserved (for example, by elective embolisation) and it is probably underused in the UK. This study highlights the high recurrence rate of pneumothorax and chylous effusion in patients with LAM; these patients should be managed in conjunction with a thoracic surgeon. Pregnancy was associated with a high risk of complications, as has been suggested by case reports, and patients need to be aware of this. Screening for TSC was performed infrequently and is probably only indicated if there is any suspicion of TSC after careful history and clinical examination. Recommenda- tions for hormonal therapy are more contentious as none is of proven efficacy, although the evidence is probably best for the use of progesterone. ${ }^{12}{ }^{13} \beta$ agonists are effective in some patients and a trial of treatment in patients with airflow obstruction seems warranted.

Unfortunately there are still no definitive data regarding survival, optimal mode of diagnosis, or hormone treatment and such questions need to be answered by specifically designed studies. We thank Drs Sarah Lewis and Andrea Venn for advice on data
analysis and the Mason Medical Foundation and the LAM analysis and the Mason Medical Foundation and the LAM
Trust (UK) for financial support. SJ was also supported by the Trust (UK) for financial support. SJ was also supported by the
LAM Foundation. We also thank the following physicians who LAM Foundation. We also thank the following physicians who
allowed us to study their patients: Dr A Johnson, Dr I C Patterallowed us to study their patients: Dr A Johnson, Dr I C Patter-
son, Mr W E Morgan, Mr F D Salama, Dr P C Barnes, Dr B D son, Mr W E Morgan, Mr F D Salama, Dr P C Barnes, Dr B D
Linaker, Dr D S Lawrence, Dr P A Corris, Dr A J Williams, Dr Linaker, Dr D S Lawrence, Dr P A Corris, Dr A J Williams, Dr
J G Williams, Dr D J Lane, Professor A J Newman-Taylor, Dr G C Ferguson, Dr M Phillips, Dr G Anderson, Dr P Jenkins, Dr W G Middleton, Dr D Ellis, Dr S J Williams, Dr M J Smith, Dr I W Fawcett, Dr R W Heaton, Dr J W Hadfield, Dr J M Wales, Dr G R Petrie, Dr A Greening, Dr S W Banham, Dr M R Partridge, Dr M G Harries, Dr N McI Johnson, Dr D M Geddes, Dr B P Madden, Dr A Alexander, Dr T J Baird, Dr J Lyall, Professor B Corrin, Dr R Dent, Dr I D A Johnston. Dr M Winterton, Professor N C Thompson, Dr M Carroll, Dr M Woodhead, Dr A J Dyson, Dr J White, Dr G F Benfield, Dr M Ward.

Funding: The Mason Medical Foundation and the UK LAM Trust.

1 Taylor JR, Ryu J, Colby TV, et al. Lymphangioleiomyomatois, clinical course in 32 patients. N Engl $7 \mathrm{Med}$ 1990;323:1254-60.

2 Kitaichi M, Nishimura K, Itoh $\mathrm{H}$, et al. Pulmonary lymphangioleiomyomatosis: a report of 46 patients including a clinicopathologic study of prognostic factors. $A m$ F Respir Crit Care Med 1995;151:527-33.

3 Corrin B, Liebow AA, Friedman PJ. Pulmonary lymphangioleiomyomatosis. Am F Pathol 1975;79:348-82.

4 Ernst JC, Sohaey R, Cary JM. Pelvic lymphangioleiomyomatosis: atypical precursor to pulmonary disease. Chest 1994;106:1267-9.

5 Maziak DE, Kesten S, Rappaport DC, et al. Extrathoracic angiomyolipomas in lymphangioleiomyomatosis. Eur Respir 7 1996;9:402-5.

6 Bernstein SM, Newell JD, Adamczyk D, et al. How common are renal angiomyolipomas in patients with lymphangioleiomyomatosis? Am $\mathcal{F}$ Respir Crit Care Med 1995;152: leiomyomat $2138-43$.

7 Chu SC, Horiba K, Usuki J, et al. Comprehensive evaluation of 35 patients with lymphangioleiomyomatosis. Chest 1999;115:1041-52.

8 Castro M, Shepherd CW, Gomez MR, et al. Pulmonary tuberous sclerosis. Chest 1995;107:189-95.

9 Stovin PGI, Lim LC, Flower CDR, et al. The lungs in lymphangioleiomyomatosis and in tuberous sclerosis. Thorax 1975;30:49.

10 Shen A, Iseman, MD, Waldron JA, et al. Exacerbation of pulmonary lymphangioleiomyomatosis by exogenous estrogens. Chest 1987;91:782-5.

11 Brentani MM, Carvalho CRR, Saldiva PH, et al. Steroid receptors in pulmonary lymphangioleiomyomatosis. Chest 1984;85:96-9.

12 Eliasson AH, Phillips YY, Tenholder MF. Treatment of lymphangioleiomyomatosis: a meta-analysis. Chest 1989; 196:1352-5.

13 Johnson SR, Tattersfield AE. Decline in lung function in patients with lymphangioleiomyomatosis: effect of menopause and progesterone treatment. Am $\mathcal{F}$ Respir Crit Care Med 1999;160:628-33.

14 Quanjer PhH, ed. Standardisation of lung function tests: 1993 update. Report of Working Party for the European Community for Steel and Coal. Eur Respir $\mathcal{f}$ 1993; 6(Suppl): 16 .

15 Urban T, Lazor R, Lacronique $\mathrm{M}$, et al. Pulmonary ymphangioleiomyomatosis: a study of 69 cases. Medicine 1999;78:321-37.

16 Burger CD, Hyatt RE, Staats BA. Pulmonary mechanics in lymphangioleiomyomatosis. Am Rev Respir Dis 1991;143: 1030-3.

17 Calvo E, Amarillas L, Mateos MA, et al. Lymphangioleiomyomatosis chylous ascites and diet. Dig Dis Sci 1996;41: 591-3.

18 Bosniak MA. Angiomyolipoma (hamartoma) of the kidney: a preoperative diagnosis is possible in virtually every case. Urol Radiol 1981;3:135-42. 
19 Van Baal JG, Smits NJ, Keeman JN, et al. The evolution of renal angiomyolipomas in patients with tuberous sclerosis. renal angiomyolipomas

20 Steiner MS, Goldman SM, Fishman EK, et al. The natural history of renal angiomyolipoma. $\mathcal{F}$ Urol 1993;150:1782-6.

21 Valensi QJ. Pulmonary lymphangiomyoma, a probable forme fruste of tuberous sclerosis. Am Rev Respir Dis 1973; 108:1411-5.

22 Warren SE, Lee D, Martin V, et al. Pulmonary lymphangiomyomatosis causing bilateral pneumothorax during pregnancy. Ann Thoracic Surg 1993;55:998-1000.

23 Brunelli A, Catalini G, Fianchini A. Pregnancy exacerbating chylothorax. Int f Gynecol Obstet 1996;52:289-90.
24 Hughes E. Hodder RV. Pulmonary lymphangiomyomatosis complicating pregnancy. A case report. $\mathcal{F}$ Reprod Med 1987; 32:553-7

25 Wahedna I, Cooper S, Williams J, et al. Relation of pulmonary lymphangioleiomyomatosis to use of the oral contraceptive pill and fertility in the UK: a national case control study. Thorax 1994;49:910-4.

26 Josen $\mathrm{K}$, Corbridge $\mathrm{T}$. Bronchodilator responsiveness in lymphangioleiomyomatosis. Am $\mathcal{F}$ Respir Crit Care Med 1999;159:A706

27 Johnson SR. Lymphangioleiomyomatosis: clinical features, management and basic mechanisms. Thorax 1999;54:25464. 